•生物编目・

\title{
基于红外相机技术的皖南山区森林生态系统 兽类资源现状
}

\author{
刘 凯 ${ }^{1}$ 贺 君 ${ }^{1}$ 张继辉 $^{1}$ 冯 俊 ${ }^{1}$ 宇 强 ${ }^{1}$ 顾长明 $^{2}$ 吴海龙 $^{1 *}$ \\ 1 (安徽省重要生物资源保护与利用研究重点实验室, 安徽师范大学生命科学学院, 安徽芜湖 241000) \\ 2 (安徽省自然保护管理站, 合肥 230001)
}

\begin{abstract}
摘要：晥南山区是安徽省陆生脊椎动物资源最丰富的动物地理区域, 为获得该区域森林生态系统中兽类资源的概 况，本研究于2013年7月至2015年10月利用红外相机技术对该区8个省级以上自然保护区(或风景名胜区)的兽类资 源进行调查, 并通过与文献记录进行比较, 分析该区兽类资源的变化趋势及其原因。本研究共布设了121个相机位 点, 其中有效相机位点 109 个, 累计 6,375 个相机工作日, 共获得兽类有效独立照片 1,361 张, 鉴定兽类 5 目 12 科 19 种。拍摄率和相对丰富度较高的前5种依次为小鹿(Muntiacus reevesi)、野猪(Sus scrofa)、藏酋猴(Macaca thibetana)、 赤腹松鼠(Callosciurus erythraeus)和猪獾(Arctonyx collaris), 除藏酋猴外, 其他4种以及果子狸(Paguma larvata)在 皖南山区广泛分布。就所监测到的国家重点保护动物而言, 猕猴(Macaca mulatta) 的相对丰富度约为藏酋猴的 $2 / 5$, 黑鹿(Muntiacus crinifrons)约为小麂的 $1 / 5$, 黄喉貂(Martes flavigula)和中华鬛羚(Capricornis milneedwardsii)均不到 黑鹿的 $1 / 4$, 而黑熊(Ursus thibetanus) 在所监测到的兽类中相对丰富度最低。与30多年前的历史记录相比, 除黑熊 外, 大中型食肉目动物无一拍摄记录, 暗示皖南山区森林生态系统中的豹(Panthera pardus)、云豹(Neofelis nebulosa)、狼(Canis lupus)等顶级捕食者已极其稀少, 或已消失, 而草食性的小鹿和杂食性的野猪成为该区相对丰富度 最高的前两种兽类。广义线性模型(generalized linear model)分析结果显示, 在 2 个月的监测时间内, 红外相机捕获 的物种数与调查区域面积 $(z=2.04, P=0.04)$ 和有效独立照片数 $(z=2.10, P=0.04)$ 呈正相关, 而与有效相机位点数 $(z=1.63, P=0.10)$ 以及相机工作日 $(z=1.85, P=0.06)$ 无显著相关性。本研究结果客观地反映出晥南山区森林生态 系统大中型兽类资源现状, 为后续针对国家重点保护兽类开展动态监测以及保护和管理提供了基础资料。
\end{abstract}

关键词：红外相机技术; 自然保护区; 拍摄率; 相对丰富度; 大中型兽类

\section{Mammal resource status in the mountain forest ecosystems of southern Anhui Province based on camera trap data}

Kai Liu ${ }^{1}$, Jun $\mathrm{He}^{1}$, Jihui Zhang ${ }^{1}$, Jun Feng ${ }^{1}$, Qiang $\mathrm{Yu}^{1}$, Changming $\mathrm{Gu}^{2}$, Hailong $\mathrm{Wu}^{1 *}$

1 Key Laboratory for the Conservation and Utilization of Important Biological Resources, Anhui Province; College of Life Sciences, Anhui Normal University, Wuhu, Anhui 241000

2 Nature Protection and Administration Station of Anhui Province, Hefei 230001

\begin{abstract}
To examine the diversity and abundance of mammals in the mountain forest ecosystems of southern mountainous areas in Anhui Province, a total of 121 cameras were installed at eight sample plots including two national and five provincial nature reserves and the Huangshan Mountain Scenic Area between July 2013 and October 2015. In total, 6,375 trap days and 1,361 effective independent photographs were collected. 19 species belonging to 5 orders and 12 families were recorded. The first five species of photographic rate and relative abundance index were Muntiacus reevesi, Sus scrofa, Macaca thibetana, Callosciurus erythraeus, and Arctonyx collaris. Except Macaca thibetana, the other four species among the five and Paguma larvata were widely distributed in mountainous areas of south Anhui Province. For those species under special state protection, the relative abundance index of Macaca mulatta was nearly two fifths of
\end{abstract}

收稿日期: 2017-02-07; 接受日期: 2017-05-12

基金项目：科技部基础性工作专项(2015FY110200)和安徽省林业厅专项基金(2016FACJ2001)

* 通讯作者 Author for correspondence. E-mail: whlong@mail.ahnu.edu.cn 
Macaca thibetana; the relative abundance index of Muntiacus crinifrons was nearly one fifth of Muntiacus reevesi; Martes flavigula and Capricornis sumatraensis was about one fourth of Muntiacus crinifrons. The relative abundance index of Ursus thibetanus was minimal among these recorded species. Compared to historical records collected thirty years ago, Ursus thibetanus was the sole large species in Carnivora captured by camera traps in this study, which indicates that the top predators, including Panthera pardus, Neofelis nebulosa, Canis lupus and Cuon alpines, were extremely sparse or had vanished from this area. As a result, the vegetarian Muntiacus reevesi and omnivorous Sus scrofa had the highest abundance amongst those mammals in this area. Correlation analysis with generalized linear models indicated that the number of species captured by infrared cameras positively correlated with the surveyed area $(z=2.04, P=0.04)$ and effective independent photographs $(z=2.10, P=0.04)$, while it did not associate with effective camera sites $(z=$ 1.63, $P=0.10)$ and total trap days $(z=1.85, P=0.06)$. Results of this study provide baseline data for a follow-up to the dynamic monitoring, protection and management of key national protected mammals.

Key words: camera traps; nature reserve; photographic rate; relative abundance; large and medium-size mammal

皖南山区地处亚热带季风气候区, 地形复杂, 森林生态系统保存较好, 是安徽省陆生野生脊椎动 物多样性最为丰富的区域, 也是华东地区的生物多 样性热点区域(王岐山, 1986)。王岐山等(1966)对安 徽兽类的地理分布进行了初步分析, 其中记录到皖 南地区兽类56种; 黄文几等(1978)对安徽哺乳动物 区系进行了较为深入的研究, 记录皖南地区有兽类 72种; 王岐山等(1981)记录黄山风景区兽类8目 19 科49种。此外, 梁仁济和董永文(1984)曾针对皖南地 区翼手目动物开展过专项研究, 记录该区翼手类29 种; 徐亚君等(1985)记录徽州地区蝙蝠19种; 刘春 生等(1986)对黄山啮齿类区系组成开展了专项调查, 记录该区啮齿类20种。

关于大中型兽类, 胡小龙等(1995)对皖南黑熊 (Ursus thibetanus)资源的分布和数量进行了专项调 查, 提出栖息地丧失和乱捕滥猎是导致皖南黑熊资 源栖息地片断化和种群下降的主要原因。韩德民等 (1995)基于皮张收购资料以及访问调查等方法对安 徽豹猫(Prionailurus bengalensis)资源的专项调查, 提出由于灭鼠药的大量使用导致豹猫种群数量明 显下降, 且从年皮张收购量来看, 直接狩猎也是该 物种野生种群数量快速下降的主要原因之一。徐宏 发等(1998)对皖南地区华南梅花鹿(Cervus nippon) 的分布和现状进行了调查, 发现皖南梅花鹿栖息地 破碎化严重, 狩猎、栖息地丧失和不断增长的放牧 等因素是导致该物种野生种群下降的主要原因。

自《野生动物保护法》(1988)颁布以来, 皖南 各地传统的狩猎方式逐渐得到控制, 森林资源的乱
砍滥伐现象也基本得到遏制。然而，针对中国南方 山区的森林兽类, 基于动物活动痕迹的调查方法往 往难以奏效(肖治术等, 2014)。近二十多年来, 鲜有 针对皖南山区兽类区系组成和特定物种的专项调 查报道, 各自然保护区兽类本底资源的调查多半引 用历史文献记录。红外相机技术可以在研究对象不 被干扰的情况下实现全天候不间断监测, 为森林生 态系统中的兽类资源调查和监测提供了新途径 (O’Connell et al, 2011; 张履冰等, 2014), 已被广泛 应用于野生动物多样性调查与监测, 以及动物行为 和生态等方面的研究(Sanderson \& Trolle, 2005; 刘 芳等, 2012; 李峰和蒋志刚, 2014)。

我们于2013年7月至2015年10月利用红外相机 技术对皖南山区森林生态系统兽类资源进行了初 步调查, 以期获得该区域兽类资源现状(各物种的 相对丰富度), 并通过与文献记录进行比较, 分析皖 南地区兽类物种组成变化及其原因, 为后续针对国 家重点保护兽类物种开展动态监测以及保护和管 理提供基础资料。

\section{1 研究方法}

\section{1 研究区域自然概况}

皖南山区位于安徽省南部, 西南和东南分别毗 邻江西和浙江, 北与沿江平原相接。地形以中、低 山为主, 九华山、黄山以及白际-天目山3条近似平 行的山脉呈西南至东北方向横贯全境, 山脉之间分 布有串珠状的山谷和盆地。黄山莲花峰海拔 $1,873 \mathrm{~m}$, 为安徽省最高峰。皖南山区属中亚热带湿润季风气 候, 年均降水量1,200-1,700 mm, 年均日照时数为 
$1,800-2,100 \mathrm{~h}$, 年均气温 $15.4-16.3^{\circ} \mathrm{C}$, 无霜期约 230 天。主要地带性植被为亚热带常绿阔叶林、常绿阔 叶与落叶阔叶混交林, 以及部分针叶林和竹林。

\section{2 红外相机调查区域}

目前, 皖南山区具有典型和代表意义的天然林 基本上都建立了国家级或省级自然保护区。本研究旨 在获得该区域大中型兽类物种组成概况, 为保证调查
区域能够充分代表皖南山区森林生态系统，同时最 大限度降低监控期间红外相机的丢失概率, 选择了 牯牛降和清凉峰 2 个国家级自然保护区，贵池老山、 休宁岭南、祁门查湾、宁国板桥和青阳盘台等5个 省级自然保护区，以及黄山风景区共8个区域。各调 查区域的详细信息以及调查时间和红外相机数见表 1 和图1。

\section{表1 本研究各调查区域基本概况及红外相机数(括号内为核心区面积)}

Table 1 Location of study areas and the number of camera used for each surveyed area in this study (Numbers in the bracket are core zone area of the nature reserve)

\begin{tabular}{|c|c|c|c|c|c|}
\hline & $\begin{array}{l}\text { 东经 } \\
\text { East longitude }\end{array}$ & $\begin{array}{l}\text { 北纬 } \\
\text { North latitude }\end{array}$ & $\begin{array}{l}\text { 面积 } \\
\text { Area (ha) }\end{array}$ & $\begin{array}{l}\text { 调查时间 } \\
\text { Survey time }\end{array}$ & $\begin{array}{l}\text { 相机数 } \\
\text { Number of camera }\end{array}$ \\
\hline $\begin{array}{l}\text { 黄山风景区 } \\
\text { Huanghan Mountain Scenic Area (HS) }\end{array}$ & $118^{\circ} 01^{\prime}-118^{\circ} 17^{\prime}$ & $30^{\circ} 01^{\prime}-30^{\circ} 18^{\prime}$ & 16,060 & 2015.5-2015.10 & 36 \\
\hline $\begin{array}{l}\text { 牯牛降国家级自然保护区 } \\
\text { Guniujiang National Nature Reserve (GNJ) }\end{array}$ & $117^{\circ} 15^{\prime}-117^{\circ} 34^{\prime}$ & $29^{\circ} 59^{\prime}-30^{\circ} 06^{\prime}$ & $6,713(3,147)$ & 2015.8-2015.12 & 29 \\
\hline $\begin{array}{l}\text { 清凉峰国家级自然保护区 } \\
\text { Qingliangfeng National Nature Reserve (QLF) }\end{array}$ & $118^{\circ} 45^{\prime}-118^{\circ} 53^{\prime}$ & $30^{\circ} 03^{\prime}-30^{\circ} 09^{\prime}$ & $7,811(2,543)$ & 2014.1-2014.3 & 18 \\
\hline $\begin{array}{l}\text { 老山省级自然保护区 } \\
\text { Laoshan Provincial Nature Reserve (LS) }\end{array}$ & $117^{\circ} 39^{\prime}-117^{\circ} 48^{\prime}$ & $30^{\circ} 19^{\prime}-30^{\circ} 27^{\prime}$ & $13,855(4,284)$ & 2013.7-2013.11 & 24 \\
\hline $\begin{array}{l}\text { 岭南省级自然保护区 } \\
\text { Lingnan Provincial Nature Reserve (LN) }\end{array}$ & $118^{\circ} 36^{\prime}-118^{\circ} 40^{\prime}$ & $30^{\circ} 28^{\prime}-30^{\circ} 33^{\prime}$ & $5,000(226.7)$ & 2014.5-2014.7 & 8 \\
\hline $\begin{array}{l}\text { 板桥省级自然保护区 } \\
\text { Banqiao Provincial Nature Reserve (BQ) }\end{array}$ & $119^{\circ} 10^{\prime}-119^{\circ} 20^{\prime}$ & $29^{\circ} 23^{\prime}-30^{\circ} 05^{\prime}$ & $2,771(800)$ & 2014.5-2014.7 & 7 \\
\hline $\begin{array}{l}\text { 查湾省级自然保护区 } \\
\text { Zhawan Provincial Nature Reserve (ZW) }\end{array}$ & $117^{\circ} 31^{\prime}-117^{\circ} 33^{\prime}$ & $29^{\circ} 37^{\prime}-29^{\circ} 39^{\prime}$ & $1,600(453)$ & 2014.3-2014.6 & 7 \\
\hline $\begin{array}{l}\text { 盘台省级自然保护区 } \\
\text { Pantai Provincial Nature Reserve (PT) }\end{array}$ & $117^{\circ} 39^{\prime}-117^{\circ} 48^{\prime}$ & $30^{\circ} 19^{\prime}-30^{\circ} 27^{\prime}$ & $540(206)$ & 2014.7-2014.9 & 4 \\
\hline
\end{tabular}

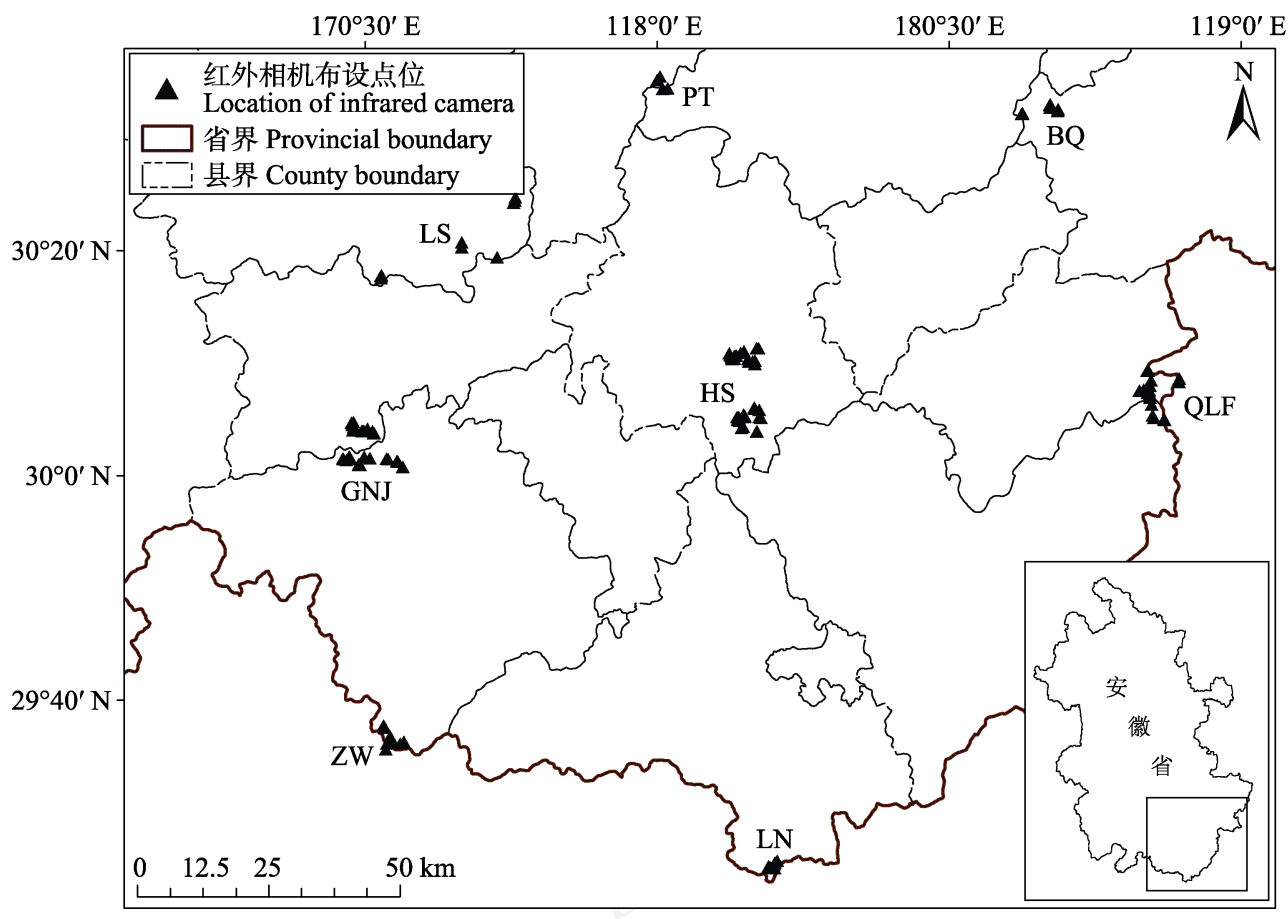

图1 调查区域及红外相机位点分布图。各区域名称缩写见表1。

Fig. 1 Maps showing study areas and infrared camera locations in this study. Acronym for each surveyed area are shown in Table 1. 


\section{3 相机布设}

根据皖南各自然保护区现状, 以及区域内大中 型兽类的活动习性, 为最大限度地捕获多数物种信 息和降低红外相机丢失概率, 本研究红外相机主要 放置在各保护区的核心区和缓冲区。首先将各保护 区划分为 $1 \mathrm{~km} \times 1 \mathrm{~km}$ 的公里网格, 在核心区和缓冲 区抽取 30-50\%的网格放置红外相机, 每个网格内 放置至少 1 台, 每两台之间间隔不少于 $300 \mathrm{~m}$, 每 台放置时间至少 2 个月。相机主要布设在海拔 500-1,000 m的常绿阔叶林以及常绿阔叶与落叶阔 叶混交林中, 选择动物活动痕迹(粪便、足迹、水源 等)较多的地点安装相机, 相机离地面高度0.3-0.4 $\mathrm{m}$, 根据地形调节相机使镜头基本与地面平行。详 细记录相机编号、GPS位点、安装时间等。相机型 号为Ltl-6210MC数字相机, 照片为 500 万像素, 每 台相机装有 8 G的SD存储卡和12节AA电池。拍摄模 式为24 h连续工作, 两次拍照的最短间隔为 $0.8 \mathrm{~s}$; 每次触发后拍照3张和1段30 s 的视频。各调查区域 的监测时间、相机数以及相机工作日见附录 1 。

\section{4 数据处理与分析}

按相机编号建立文件夹, 每台相机所拍摄的照 片分别存入相应的文件夹。删除空白照片和视频, 确定能够鉴别物种的有效照片和视频。对于同一相 机位点上拍摄的同一物种连续照片, 以时间间隔大 于 $30 \mathrm{~min}$ 作为 1 次独立捕获, 记录为 1 张独立照片 (O’Brien et al, 2003)。分别统计各物种出现的照片总 数和独立照片数。依据蒋志刚等(2015)的分类系统 对所监测到的物种进行分类。

分别统计各调查区域以及皖南山区的物种相 对丰富度(relative abundance, $\mathrm{RA}$ ): $\mathrm{RA}=A_{\mathrm{i}} / N$, 其中, $A_{\mathrm{i}}$ 为第 $\mathrm{i}$ 种兽类的独立照片数; $N$ 为相应调查区域内 所拍摄兽类总的独立照片数。

分别统计各调查区域以及皖南山区的物种拍 摄率(photographic rate, PR): PR $=100 N_{\mathrm{j}} / T$, 其中, $N_{\mathrm{j}}$ 指第 $\mathrm{j}$ 种动物的独立照片数; $T$ 为相应区域总的相 机工作日。

在R3.1.1软件中, 利用vegan软件包中的稀疏曲 线法(rarefaction curve)拟合各调查区域捕获的兽类 物种数与相机工作日之间的关系, 以检验抽样强度 是否充分。利用广义线性模型 (generalized linear model, GLM)分别对各保护区所监测到的物种数量 与保护区面积、相机工作日、独立有效照片数等变 量之间的相关性进行分析。针对数量数据, 使用 Poisson分布进行模型拟合, 根据模型的 HF值(残差 /df)判定数据组与Poisson分布的符合程度, 较大的 $H F$ 值 $(H F>1)$ 意味着偏离Poisson分布, 会导致显著 性检验程度被高估。

\section{2 结果}

\section{1 红外相机监测概况}

本研究在 8 个调查区域共布设了 121 个相机位 点, 因丢失或操作失误、恶劣气候等因素导致未能 正常工作的相机位点12个。其中, 清凉峰自然保护 区的监测时间在冬季(2014.1-2014.3), 无效相机位 点数最多 (5个), 可能与冬季的低温和雨雪天气有关。 共有109个相机位点正常工作时间超过 1 个月, 累积 6,375 个相机工作日(表2)。共获得12,022张拍摄到动 物的照片, 其中, 可鉴别兽类物种的有效照片 4,828 张,

表2 皖南山区各调查区域红外相机拍摄结果以及兽类物种数量。各调查区域名称缩写见表 1 。

Table 2 Camera trapping efforts and mammal species identified from the photos in all surveyed areas in south Anhui Province. Acronyms for each surveyed area are shown in Table 1.

\begin{tabular}{lllll}
\hline & $\begin{array}{l}\text { 有效相机位点数 } \\
\text { Number of sites }\end{array}$ & $\begin{array}{l}\text { 相机工作日 } \\
\text { Camera days }\end{array}$ & $\begin{array}{l}\text { 独立有效照片数 } \\
\text { Number of photos }\end{array}$ & $\begin{array}{l}\text { 物种数 } \\
\text { Number of species }\end{array}$ \\
\hline 黄山风景区 HS & 34 & 2,019 & 474 & 14 \\
牯牛降国家级自然保护区 GNJ & 28 & 1,498 & 257 & 12 \\
清凉峰国家级自然保护区 QLF & 13 & 637 & 99 & 8 \\
老山省级自然保护区 LS & 12 & 966 & 232 & 15 \\
岭南省级自然保护区 LN & 7 & 382 & 55 & 9 \\
板桥省级自然保护区 BQ & 7 & 405 & 163 & 12 \\
查湾省级自然保护区 ZW & 5 & 287 & 58 & 9 \\
盘台省级自然保护区 PT & 3 & 181 & 23 & 6 \\
合计 Total & 109 & 6,375 & 1,361 & 19 \\
\hline
\end{tabular}


表3 皖南山区各调查区域的兽类物种相对丰富度。各调查区域名称缩写见表 1 。

Table 3 Relative species abundance based on camera trapping for each surveyed area in south Anhui Province. Acronyms for each surveyed area are shown in Table 1.

\begin{tabular}{|c|c|c|c|c|c|c|c|c|c|}
\hline \multirow{2}{*}{$\begin{array}{l}\text { 物种 } \\
\text { Species }\end{array}$} & \multicolumn{9}{|c|}{ 相对丰富度 Relative abundance (\%) } \\
\hline & $\begin{array}{l}\text { 黄山风景区 } \\
\text { HS }\end{array}$ & $\begin{array}{l}\text { 牯牛降 } \\
\text { GNJ }\end{array}$ & $\begin{array}{l}\text { 清凉峰 } \\
\text { QLF }\end{array}$ & $\begin{array}{l}\text { 老山 } \\
\text { LS }\end{array}$ & $\begin{array}{l}\text { 查湾 } \\
\mathrm{ZW}\end{array}$ & $\begin{array}{l}\text { 岭南 } \\
\text { LN }\end{array}$ & $\begin{array}{l}\text { 盘台 } \\
\text { PT }\end{array}$ & $\begin{array}{l}\text { 板桥 } \\
\mathrm{BQ}\end{array}$ & $\begin{array}{l}\text { 合计 } \\
\text { Total }\end{array}$ \\
\hline 赤腹松鼠 Callosciurus erythraeus & 8.86 & 21.01 & 9.09 & 7.33 & 7.02 & 1.82 & 8.70 & 4.29 & 9.99 \\
\hline 倭花鼠 Tamiops maritimus & 0.63 & 6.61 & & 1.29 & & & & & 1.69 \\
\hline 中国豪猪 Hystrix hodgsoni & 1.27 & 0.39 & & & 7.02 & & & 0.61 & 0.88 \\
\hline 黑熊 Ursus thibetanus & & & & & 1.72 & & & & 0.07 \\
\hline 豹猫 Prionailurus bengalensis & 0.42 & & & 0.43 & & & & & 0.22 \\
\hline 黄喉貂 Martes flavigula & 1.48 & 0.39 & & 2.16 & & 5.45 & & 1.23 & 1.32 \\
\hline 黄鼠 Mustela sibirica & 0.84 & 0.78 & & 1.29 & 10.53 & & & 0.61 & 1.18 \\
\hline 鼠獾 Melogale moschata & & & & 0.86 & & & & & 0.15 \\
\hline 狗獾 Meles leucurus & & & & & & & & 1.23 & 0.15 \\
\hline 猪獾 Arctonyx collaris & 4.43 & 3.50 & 4.04 & 11.21 & 15.79 & 9.09 & 8.70 & 11.04 & 6.91 \\
\hline 果子狸 Paguma larvata & 4.22 & 7.78 & 3.03 & 10.34 & 5.26 & 3.64 & 13.04 & 11.04 & 6.83 \\
\hline 食蟹獴 Herpestes urva & & & & 1.72 & & & & & 0.29 \\
\hline 野猪 Sus scrofa & 10.78 & 24.51 & 23.23 & 22.41 & 7.02 & 5.45 & 4.35 & 2.45 & 14.77 \\
\hline 小鹿 Muntiacus reevesi & 33.76 & 19.84 & 28.28 & 17.67 & 35.09 & 50.91 & 52.17 & 25.15 & 27.99 \\
\hline 黑鹿 Muntiacus crinifrons & 4.64 & 9.34 & 4.04 & 6.03 & & 18.18 & 13.04 & & 5.66 \\
\hline 中华镾羚 Capricornis milneedwardsii & 0.21 & 2.72 & 2.02 & 1.29 & & 3.64 & & 1.23 & 1.25 \\
\hline 猕猴 Macaca mulatta & 1.05 & & & 3.88 & 12.28 & 1.82 & & 34.35 & 5.73 \\
\hline 藏酋猴 Macaca thibetana & 27.42 & 3.11 & & 12.07 & & & & 6.75 & 13.01 \\
\hline 华南兔 Lepus sinensis & & & 26.26 & & & & & & 1.91 \\
\hline
\end{tabular}

占比 $40.16 \%$; 可鉴别鸟类物种的照片 4,400 张，占比 $36.6 \%$ ，其余为夜行性啮齿类或因距离过远而无法 鉴别物种的照片。在 4,828 张兽类照片中, 独立有效 照片1,361张(表2), 经鉴定，隶属5目12科19种(表3)。

\section{2 皖南山区森林兽类资源概况}

在基于红外相机监测所鉴定出的19种兽类中, 有国家I级重点保护动物 1 种, 即黑鹿 (Muntiacus crinifrons), 国家II级重点保护动物5种, 即黑熊、黄

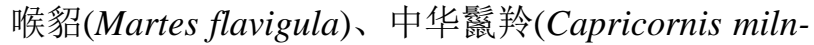
eedwardsii)、猕猴(Macaca mulatta) 和藏酋猴(M. thibetana); 列入IUCN (2016) (http://www.iucnredlist.org/) 红色名录的易危种 2 种, 近危种 8 种; 列入CITES附 录I的4种，附录II的1种(附录1)。

从类群上来看，被监测到的食肉目物种数量最 多，有5科 9 种，占所监测总物种数的 $47.37 \%$, 但这 个类群多数物种的相对丰富度并不高, 9种累积相 对丰富度仅为 $17.2 \%$ 。而且, 除黑熊外, 均为中小型 兽类。鲸偶蹄目动物 3 科 4 种, 物种数量虽不及食肉 目，但小鹿(Muntiacus reevesi)和野猪(Sus scrofa)在
各调查区域的相对丰富度均位居前列(表3)。

就皖南山区整体而言，拍摄率和物种相对丰富 度最高的前 5 种均是小鹿、野猪、藏酋猴、赤腹松 鼠 (Callosciurus erythraeus) 和猪獾 (Arctonyx collaris)(表3，附录1)。各调查区域均有拍摄记录的5种 动物是：小鹿、野猪、赤腹松鼠、猪獾和果子狸 (Paguma larvata), 且相对丰富度也较高(表3); 但一 些物种仅在某一区域出现，如：黑熊(查湾)、鼠獾 (Melogale moschata)(老山)、食蟹獴(Herpestes urva) (老山)、华南兔(Lepus sinensis)(清凉峰), 或在少数 区域出现，如: 豹猫(黄山、老山)、倭花鼠(Tamiops maritimus)(黄山、牯牛降、老山)。国家重点保护动 物藏酋猴、猕猴、黄喉貂、黑鹿和中华鬣羚在多数 调查区域均有分布，但仅藏酋猴在黄山风景区和老 山保护区具有较高的相对丰富度; 狝猴的相对丰富 度约为藏酋猴的 $2 / 5$; 黑鹿约为小鹿的 $1 / 5$; 黄喉貂 和中华镴羚的相对丰富度均不及黑鹿的 $1 / 4$; 而黑 熊的拍摄率和相对丰富度在所有监测到的物种中 最低(表3，附录1)。 


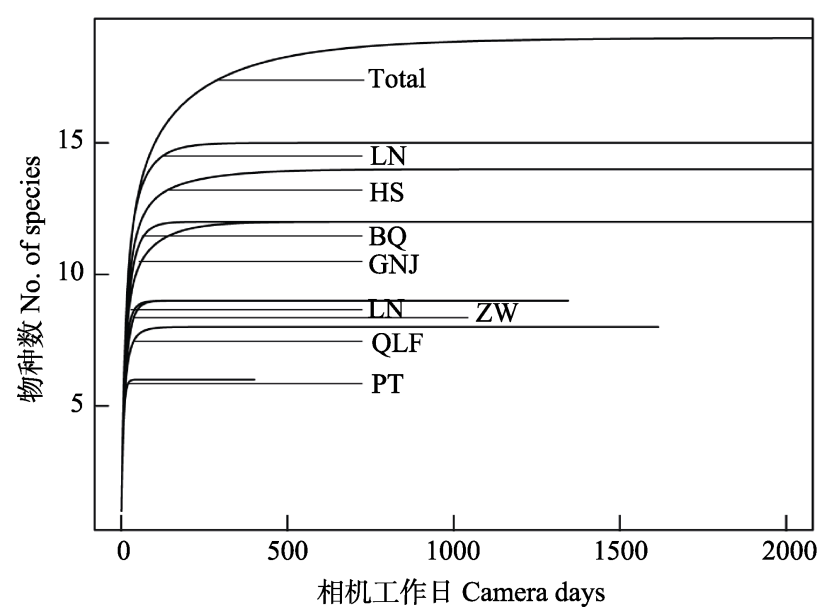

图2 皖南及各调查区域兽类物种数与相机工作日拟合的稀 疏曲线。各调查区域缩写见表1。

Fig. 2 Rarefaction curve for estimating the relationship between the number of captured species with trapping days in all surveyed areas in south Anhui Province. Acronyms for each surveyed area are shown in Table 1.

\section{3 不同调查区域兽类物种的分布}

基于红外相机监测数据, 就皖南地区兽类物种 多样性而言, 老山省级自然保护区记录到的物种数 最多, 有15种, 其次是黄山风景区(14种), 牯牛降国 家级自然保护区和板桥省级自然保护区(各12种), 岭南和查湾省级自然保护区(各9种), 清凉峰国家级 自然保护区(8种)，而盘台省级自然保护区记录到的 物种数最少, 仅6种(表2)。

稀疏曲线拟合结果显示, 就各调查区域物种数 与有效相机工作日之间的关系而言, 当相机日达到 400时, 所有保护区的物种数均趋向饱和, 实际上, 部分调查区域在相机日不到200时物种数就已经趋 向饱和。当以皖南山区为整体进行拟合时, 在相机 日达到1,000时, 物种数趋向饱和(图2)。

广义线性模型(GLM)相关性分析结果显示, 红 外相机监测到的物种数量与保护区面积 $(z=2.04, P$ $=0.04)$ 和独立有效照片数 $(z=2.10, P=0.04)$ 呈显著 正相关, 而与相机位点数 $(z=1.63, P=0.10)$ 和相机 工作日 $(z=1.85, P=0.06)$ 之间的相关性不显著, 但所 监测到的物种数呈现出随相机工作日增加而增多的 趋势, 这与稀疏曲线起始段所预测的结果相一致。

\section{3 讨论}

本研究所选择的 8 个调查区域包含了国家级和 省级自然保护区以及黄山风景区, 能够比较全面地 代表皖南山区森林生态系统类型。物种数量与相机
工作日拟合的稀疏曲线结果表明, 本研究各调查区 域的抽样强度均比较充分(图2)。《安徽兽类志》记 录皖南地区兽类83种(王岐山，1990), 其中食虫目3 科 5 种, 啮齿目 5 科 20 种, 兔形目和鳞甲目各 1 科 1 种, 灵长目 1 科 2 种, 食肉目 5 科 20 种, 偶蹄目 3 科 8 种。由 于红外相机拍摄技术自身的特点, 难以对夜间活动 的小型啮齿类和营飞行生活的翼手类进行有效监 测, 即使拍摄到照片, 有时也难以进行准确的物种 识别。因此, 本文仅对皖南山区大中型兽类(包括食 肉目、偶蹄目和灵长目动物)以及通过外形易于识别 的松鼠科动物区系组成变化及其原因进行分析。

在 3 个大中型类群中, 灵长目物种组成没有变 化, 其种群数量虽难以与历史数据进行对比, 但藏 酋猴的相对丰富度仅次于小鹿和野猪, 而在半数以 上保护区有拍摄记录, 表明这两种灵长目动物在皖 南山区至少属常见物种。

食肉目变化最显著, 《安徽兽类志》曾记录皖 南地区有 5 科 20 种, 然而本次监测仅记录到 5 科 9 种 (表3, 附录1)。其中, 犬科动物未有记录, 且熊科、 猫科、灵猫科和獴科(食蟹獴从原灵猫科独立为獴科) 动物各记录 1 种, 记录物种最多的是鼠科(5种)。黑熊 是本研究唯一记录到的大型食肉动物, 20 世纪 90 年 代中期，该物种还曾分布于㪘县和休宁县的17个乡 镇以及牯牛降国家级自然保护区(胡小龙等, 1995), 但本研究仅在查湾省级自然保护区记录到1次, 岭 南和牯牛降自然保护区均无记录, 推测黑熊在皖南 的分布范围已进一步萎缩, 种群数量也明显减少。 大型猫科动物(云豹Neofelis nebulosa和豹Panthera pardus)和犬科动物(豹Cuon alpinus)在安徽主要分 布于皖南山区。第一次全国陆生野生脊椎动物调查 期间, 作者曾在牯牛降国家级自然保护区目睹群豹 捕食野猪的场景。2000年前后, 石台、休宁等地曾 在短期内多次救护过下山的小云豹(安徽省自然保 护管理站内部资料), 但此后皖南各地鲜有记录。此 外, 体型稍小的金猫(Catopuma temminckii)、大灵猫 (Viverra zibetha)和小灵猫(Viverricula indica)在所有 调查区域均无拍摄记录, 这些物种早在 20 世纪 80 年 代初就已经十分稀少(王岐山, 1990)。豹猫在皖南各 地曾有广泛分布, 也是皖南地区传统的毛皮经济动 物, 但过度猎杀、滥用鼠药以及栖息地质量退化等 因素导致其野生种群在 20 世纪80年代中后期急剧 下降(韩德民等, 1995), 本次调查仅黄山风景区和老 
山自然保护区有记录, 但物种丰富度很低(仅0.22)。 综上所述, 除中小型鼠科动物外, 自南地区大部分 食肉目动物野生种群已很稀少或在部分地区可能 已消失, 其主要原因有: 近期历史上的过度猎杀、 栖息地片断化以及滥用鼠药等。

《安徽兽类志》曾记录皖南山区偶蹄目3科8种, 其中青羊(Naemorhedus griseus)仅是历史记录, 皖 南可能并无该物种的分布(王岐山, 1990; 徐亚君, 1997)。本次利用红外相机监测记录偶蹄目 3 科4种 (表3，附录1), 其中, 小鹿和野猪在所有调查区域的 相对丰富度都位居前列, 黑鹿和中华鬌羚的分布范 围和相对丰富度虽不及小鹿和野猪, 但在半数以上 区域均有拍摄记录, 表明这两种动物在皖南的分布 范围也比较广。獐(Hydropotes inermis)喜栖息于湿 地附近的山坡灌丛, 梅花鹿则多出没于高山草甸, 二者均非典型森林兽类, 本研究未针对上述两种生 境进行监控, 没有拍摄记录当属正常。但令人意外 的是, 与小鹿和黑鹿生境需求相似的毛冠鹿 (Elaphodus cephalophus)在所有调查区域竟无一拍 摄记录, 推测其种群数量很低。在大型捕食者近乎 缺失的情况下, 毛冠鹿极低的种群密度是否与同域 分布且体型大小相近的小鹿和黑鹿竞争有关, 还有 待于进一步研究。

近年来, 皖南山区不少村民经常反映野猪对农 作物损毁严重, 要求省级林业主管部门放宽对野猪 和小麂等动物的狩猎限制。本研究监测结果显示, 野猪和小鹿确实在皖南山区有较高丰富度, 成为该 区域大中型兽类中的优势种, 这可能与区域大中型 食肉类动物种群数量较小与保护力度加强及打击 偷猎行为相关。但是否放宽狩猎限制或放宽到什么 程度, 需要对相关物种的种群与栖息地现状及潜在 的威胁因子做充分评估后, 方可做出决策, 且涉及 到狩猎的技术性问题, 特别是有针对性的狩猎, 如: 野猪。本次监测结果虽然表明小鹿、野猪在皖南山 区分布广泛, 且相对丰富度较高, 但现有数据还不 能支撑是否可放宽狩猎限制。事实上，在野外调查 过程中, 我们发现皖南山区一些保护区仍存在不同 程度的非法偷猎现象，既有传统的狩猎方式(网捕、 套捕、夹捕等), 更有利用电网等新型的狩猎工具。 这些偷猎行为很有可能伤及黑鹿、中华鬌羚等濒危 野生动物, 因此, 目前禁猎仍是物种保护特别是大 中型兽类保护的优先策略。
致谢：本研究得到安徽省自然保护管理站、皖南各 自然保护区、黄山风景区以及相关林业工作站的大 力支持; 安徽师范大学胡好远教授为本文的数据统 计提供了指导; 安庆师范大学赵凯博士为本文的制 图提供了帮助, 在此一并致谢。

\section{参考文献}

Han DM, Hu XL, Gu CM, Wang BZ (1995) An investigation on leopard cat in Anhui Province. Journal of Anhui University (Natural Sciences), (4), 82-88. (in Chinese with English abstract) [韩德民, 胡小龙, 顾长明, 王保洲 (1995) 安徽 省豹猫的分布和数量. 安徽大学学报(自然科学版), (4), 82-88.]

Hu XL, Han DM, Wang BZ, Gu CM (1995) The investigation on Asiatic black bear in Anhui Province. Journal of Anhui University (Natural Sciences), (2), 105-109. (in Chinese with English abstract) [胡小龙, 韩德民, 王保洲, 顾长明 (1995) 安徽省黑熊资源调查. 安徽大学学报(自然科学 版), (2), 105-109.]

Huang WJ, Wen YX, Huang ZY, Mu DW, Tang ZY, Lian ZC (1978) Investigation of mammals and geographical division of Anhui. Journal of Fudan University (Natural Science), (1), 86-104. (in Chinese) [黄文几, 温业新, 黄正一, 穆大 威, 唐子英, 练作宸 (1978) 安徽省哺乳动物调查和地理 区划. 复旦学报(自然科学版), (1), 86-104.]

Jiang ZG, Ma Y, Wu Y, Wang YX, Feng ZJ, Zhou KY, Liu SY, Luo ZH, Li CW (2015) China's mammalian diversity. Biodiversity Science, 23, 351-364. (in Chinese with English abstract) [蒋志刚, 马勇, 吴毅, 王应祥, 冯祚建, 周开亚, 刘少英, 罗振华, 李春旺 (2015) 中国哺乳动物多样性. 生物多样性, 23, 351-364.]

Li F, Jiang ZG (2014) Is nocturnal rhythm of Asian badger (Meles leucurus) caused by human activity? A case study in the eastern area of Qinghai Lake. Biodiversity Science, 22, 758-763. (in Chinese with English abstract) [李峰, 蒋志刚 (2014) 狗獾夜间活动节律是受人类活动影响而形成的 吗? 基于青海湖地区的研究实例. 生物多样性, 22, 758-763.]

Liang RJ, Dong YW (1984) Bats from South Anhui. Acta Theriologica Sinica, 4, 321-328. (in Chinese with English abstract) [梁仁济, 董永文 (1984) 皖南地区翼手类初步 研究. 兽类学报, 4, 321-328.]

Liu CS, Wu WN, Yu ZC, Meng JH, Zhang DR (1986) A study on the rodent fauna on Huangshan Mountain of Anhui Province. Chinese Journal of Zoology, 21(6), 18-21. (in Chinese) [刘春生, 吴万能, 俞正楚, 孟冀辉, 张大荣 (1986) 安徽省黄山啮齿类区系研究. 动物学杂志, 21(6), 18-21.]

Liu F, Li DQ, Wu JG (2012) Using infra-red cameras to survey wildlife in Beijing Songshan National Nature Reserve. Acta Ecologica Sinica, 32, 730-739. (in Chinese with English ab- 
stract) [刘芳, 李迪强, 吴记贵 (2012) 利用红外相机调查 北京松山国家级自然保护区的野生动物物种. 生态学报, 32, 730-739.]

O’Brien TG, Kinnaird MF, Wibisono HT (2003) Crouching tigers, hidden prey: Sumatran tiger and prey populations in a tropical forest landscape. Animal Conservation, 6, 131-139.

O’Connell AF, Nichols JD, Karanth KU (2011) Camera Traps in Animal Ecology: Methods and Analyses. Springer, New York.

Sanderson JG, Trolle M (2005) Monitoring elusive mammals: unattended cameras reveal secrets of some of the world's wildest places. American Scientist, 93, 148-155.

Wang QS (1986) The zoogeographical division of Anhui Province. Journal of Anhui University (Natural Sciences), (1), 45-58. (in Chinese with English abstract) [王岐山 (1986) 安徽动物地理区划. 安徽大学学报(自然科学版), (1), 45-58.]

Wang QS (1990) The Mammal Fauna of Anhui. Anhui Science and Technology Publishing House, Hefei. (in Chinese with English abstract) [王岐山 (1990) 安徽兽类志. 安徽科学 技术出版社, 合肥.]

Wang QS, Chen BH, Liang RJ (1966) The pilot study on geological distribution of mammals in Anhui Province. Chinese Journal of Zoology, 8(3), 101-106. (in Chinese with English abstract) [王岐山, 陈璧辉, 梁仁济 (1966) 安徽兽类地理 分布的初步研究. 动物学杂志, 8(3), 101-106.]

Wang QS, Hu XL, Xing QR, Xiong CP, Lin ZX (1981) An investigation of birds and mammals of Huangshan in Anhui Province. Journal of Anhui University (Natural Sciences), (2), 138-158. (in Chinese) [王岐山, 胡小龙, 邢庆仁, 熊 成培, 林祖贤 (1981) 安徽黄山的鸟兽资源调查报告. 安
徽大学学报(自然科学版), (2), 138-158.]

Xiao ZS, Li XH, Jiang GS (2014) Applications of camera trapping to wildlife surveys in China. Biodiversity Science, 22, 683-684. (in Chinese) [肖治术, 李欣海, 姜广顺 (2014) 红外相机技术在我国野生动物监测研究中的应用. 生物 多样性, 22, 683-684.]

Xu HF, Lu HJ, Sheng HL, Gu CM (1998) Status and current distribution of South China Sika Deer. Chinese Biodiversity, 6, 87-91. (in Chinese with English abstract) [徐宏发, 陆厚 基, 盛和林, 顾长明 (1998) 华南梅花鹿的分布和现状. 生物多样性, 6, 87-91.]

Xu YJ (1997) Discussion on the wild animal resources in Huangshan area. Journal of Huangshan University, 7(1), 1-11. (in Chinese) [徐亚君 (1997) 黄山市野生动物资源 论证. 黄山学院学报, 7(1), 1-11.]

Xu YJ, Cheng BG, Fang DA, Wang L (1985) A preliminary observation on Chiroptera in Huizhou Region, Anhui Province and their overwintering ecology. Acta Theriologica Sinica, 5, 87-93. (in Chinese with English abstract) [徐亚 君, 程炳功, 方德安, 汪林 (1985) 安徽省徽州地区翼手 类及其越冬生态的初步观察. 兽类学报, 5, 87-93.]

Zhang LB, Cui SP, Huang YJ, Chen DQ, Qiao HJ, Li CW, Jiang ZG (2014) Infrared camera traps in wildlife research and monitoring in China: issues and insights. Biodiversity Science, 22, 696-703. (in Chinese with English abstract) [张 履冰, 崔绍朋, 黄元骏, 陈代强, 乔慧捷, 李春旺, 蒋志 刚 (2014) 红外相机技术在我国野生动物监测中的应用: 问题与限制. 生物多样性, 22, 696-703.]

(责任编委: 蒋学龙 责任编辑: 间文杰)

\section{附录 Supplementary Material}

\section{附录1 基于红外相机调查的皖南山区兽类物种名录以及拍摄率和相对丰富度}

Appendix 1 Species list, photographic rate and relative abundance of mammals captured by camera traps in south Anhui Province http://www.biodiversity-science.net/fileup/PDF/2017031-1.pdf

\section{附录2 红外相机拍摄的皖南山区代表性兽类照片}

Appendix 2 Representative mammals recorded by camera traps in south Anhui Province http://www.biodiversity-science.net/fileup/PDF/2017031-2.pdf 
刘凯, 贺君, 张继辉, 冯俊, 宇强, 顾长明, 吴海龙. 基于红外相机技术的皖南山区森林生态系统兽类资源现状. 生物多样性, 2017, 25 (8): 896-903.

http://www.biodiversity-science.net/CN/10.17520/biods.2017031

附录 1 基于红外相机调查的皖南山区兽类物种名录以及拍摄率和相对丰富度

Appendix 1 Species list, photographic rate and relative abundance of mammals captured by camera traps in south Anhui Province

\begin{tabular}{|c|c|c|c|c|}
\hline $\begin{array}{c}\text { 物种 } \\
\text { Species }\end{array}$ & $\begin{array}{c}\text { 保护级别 } \\
\text { Protection category }\end{array}$ & $\begin{array}{c}\text { 独立照片数 } \\
\text { Number of } \\
\text { independent photos }\end{array}$ & $\begin{array}{c}\text { 拍摄率 } \\
\text { Photographic rate }\end{array}$ & $\begin{array}{l}\text { 相对丰富度 } \\
\text { Relative } \\
\text { abundance }\end{array}$ \\
\hline \multicolumn{5}{|l|}{ 灵长目 Primates } \\
\hline \multicolumn{5}{|l|}{ 猴科 Cercopithecidae } \\
\hline 1. 猕猴 Macaca mulatta & II & 78 & 1.22 & 5.73 \\
\hline 2. 藏酋猴 Macaca thibetana $\boldsymbol{\Delta}$ & II , NT, Appendix II & 177 & 2.78 & 13.01 \\
\hline \multicolumn{5}{|l|}{ 食肉目 Carnivora } \\
\hline \multicolumn{5}{|l|}{ 熊科 Ursidae } \\
\hline 3. 黑熊 Ursus thibetanus & II, VU, Appendix I & 1 & 0.02 & 0.07 \\
\hline \multicolumn{5}{|l|}{ 猫科 Felidae } \\
\hline 4. 豹猫 Prionailurus bengalensis & Appendix I & 3 & 0.05 & 0.22 \\
\hline \multicolumn{5}{|l|}{ 鼠由科 Mustelidae } \\
\hline 5. 黄喉貂 Martes flavigula & II , NT & 18 & 0.28 & 1.32 \\
\hline 6. 黄鼠 Mustela sibirica & & 16 & 0.25 & 1.18 \\
\hline 7. 鼠由獾 Melogale moschata & NT & 2 & 0.03 & 0.15 \\
\hline 8. 狗獾 Meles leucurus & NT & 2 & 0.03 & 0.15 \\
\hline 9. 猪獾 Arctonyx collaris & NT & 94 & 1.47 & 6.91 \\
\hline \multicolumn{5}{|l|}{ 灵猫科 Viverridae } \\
\hline 10. 果子狸 Paguma larvata & NT & 93 & 1.46 & 6.83 \\
\hline \multicolumn{5}{|l|}{ 獴科 Herpestidae } \\
\hline 11. 食蟹獴 Herpestes urva & NT & 4 & 0.06 & 0.29 \\
\hline \multicolumn{5}{|l|}{ 鲸偶蹄目 Cetartiodactyla } \\
\hline \multicolumn{5}{|l|}{ 猪科 Suidae } \\
\hline 12. 野猪 Sus scrofa & & 201 & 3.15 & 14.77 \\
\hline \multicolumn{5}{|l|}{ 鹿科 Cervidae } \\
\hline 13. 小鹿 Muntiacus reevesi $\boldsymbol{\Delta}$ & & 381 & 5.98 & 27.99 \\
\hline 14. 黑鹿 Muntiacus crinifrons $\boldsymbol{\Lambda}$ & I , VU, Appendix I & 77 & 1.21 & 5.66 \\
\hline \multicolumn{5}{|l|}{ 牛科 Bovidae } \\
\hline $\begin{array}{l}\text { 15. 中华瓺羚 Capricornis } \\
\text { milneedwardsii }\end{array}$ & II , NT, Appendix I & 17 & 0.27 & 1.25 \\
\hline \multicolumn{5}{|l|}{ 啮齿目 Rodentia } \\
\hline \multicolumn{5}{|l|}{ 松鼠科 Sciuridae } \\
\hline 16. 赤腹松鼠 Callosciurus erythraeus & & 136 & 2.13 & 9.99 \\
\hline 17. 倭花鼠 Tamiops maritimus & & 23 & 0.36 & 1.69 \\
\hline \multicolumn{5}{|l|}{ 豪猪科 Hystricidae } \\
\hline 18. 中国豪猪 Hystrix hodgsoni & & 12 & & 0.88 \\
\hline \multicolumn{5}{|l|}{ 兔形目 Lagomorpha } \\
\hline \multicolumn{5}{|l|}{ 兔科 Leporidae } \\
\hline 19. 华南兔 Lepus sinensis & & 26 & 0.41 & 1.91 \\
\hline
\end{tabular}

I, II 分别代表国家 I、II 级重点保护动物; VU, NT 分别代表 IUCN 红色名录中的易危种和近危种; Appendix I, II 分别代表 CITES 附录 I、 II 物 种。中国特有种。

I and II, First Class and Second Class National Key Protected Animals; VU and NT, Vulnerable and Near Threatened in IUCN Red List; Appendix I, II: CITES Appendix I, II. $\boldsymbol{\Delta}$ Endemic to China. 
刘凯, 贺君, 张继辉, 冯俊, 宇强, 顾长明, 吴海龙. 基于红外相机技术的皖南山区森林生态系统兽类资源现状. 生物多样性, 2017, 25 (8): 896-903.

http://www.biodiversity-science.net/CN/10.17520/biods.2017031

附录 2 红外相机拍摄的皖南山区代表性兽类照片

Appendix 2 Representative mammals recorded by camera traps in south Anhui Province

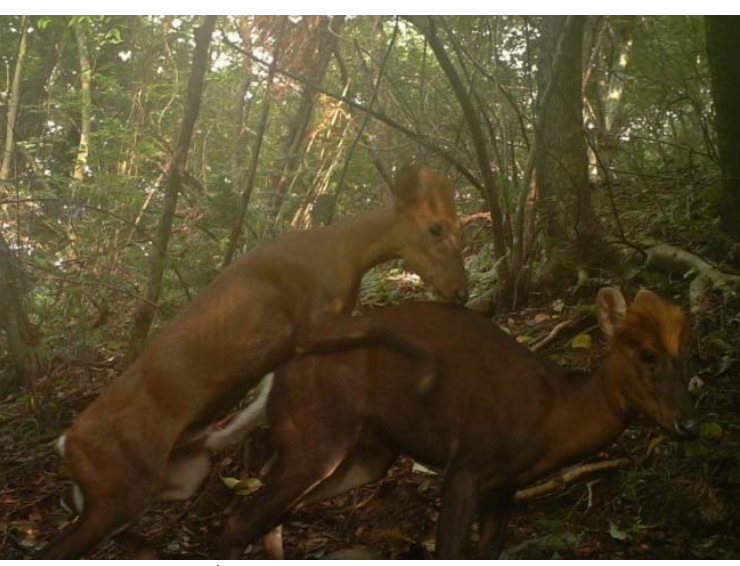

黑鹿 Muntiacus crinifrons

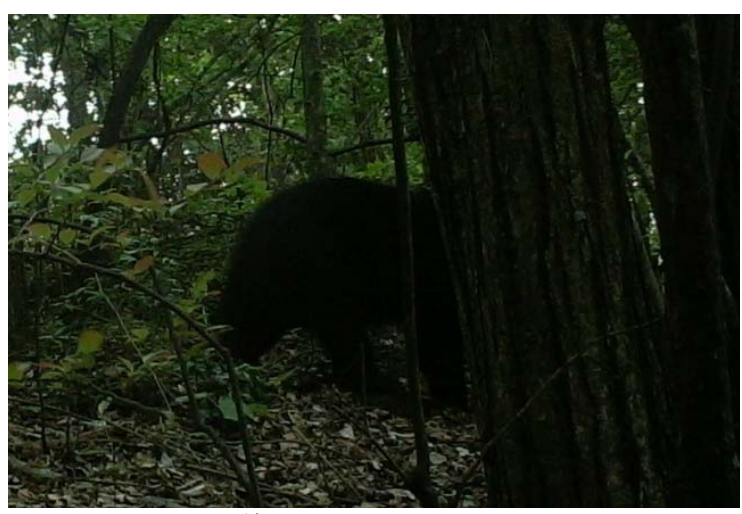

黑熊 Ursus thibetanus

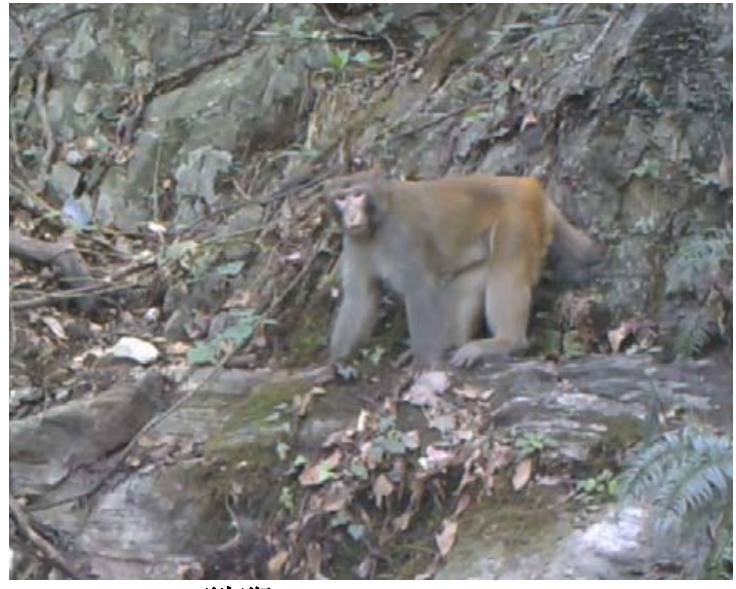

猕猴 Macaca mulatta

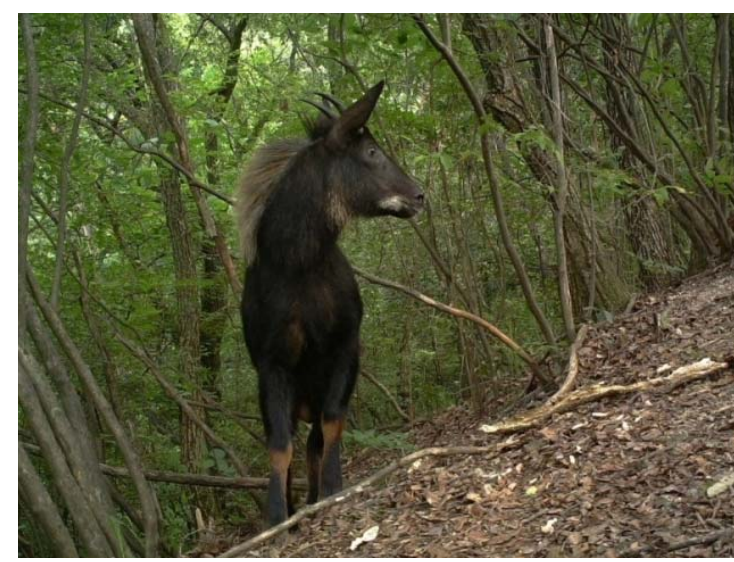

中华瓺羚 Capricornis milneedwardsii

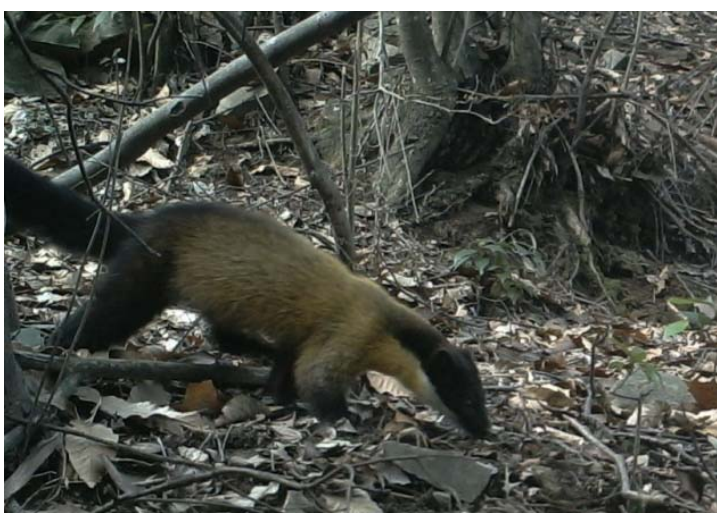

黄喉貂 Martes flavigula

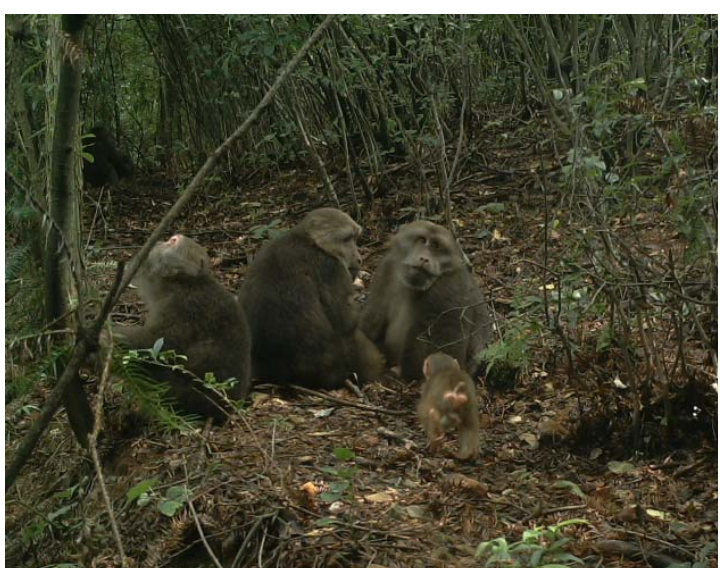

藏酋猴 (黄山短尾猴) Macaca thibetana 